\title{
Role of Visual and Olfactory Cues from Agricultural Hedgerows in the Orientation Behavior of Multicolored Asian Lady Beetle (Coleoptera: Coccinellidae)
}

\author{
Author(s): C. A. Bahlai, J. A. Welsman, E. C. Macleod, A. W. Schaafsma, R. H.
} Hallett, and M. K. Sears

Source: Environmental Entomology, 37(4):973-979. 2008.

Published By: Entomological Society of America

DOI: 10.1603/0046-225X(2008)37[973:ROVAOC]2.0.CO;2

URL:

http://www.bioone.org/doi/full/10.1603/0046-

225X\%282008\%2937\%5B973\%3AROVAOC\%5D2.0.CO\%3B2

BioOne (www.bioone.org) is an electronic aggregator of bioscience research content, and the online home to over 160 journals and books published by not-for-profit societies, associations, museums, institutions, and presses.

Your use of this PDF, the BioOne Web site, and all posted and associated content indicates your acceptance of BioOne's Terms of Use, available at www.bioone.org/page/terms_of_use.

Usage of BioOne content is strictly limited to personal, educational, and non-commercial use. Commercial inquiries or rights and permissions requests should be directed to the individual publisher as copyright holder. 


\title{
Role of Visual and Olfactory Cues from Agricultural Hedgerows in the Orientation Behavior of Multicolored Asian Lady Beetle (Coleoptera: Coccinellidae)
}

\author{
C. A. BAHLAI, ${ }^{1}$ J. A. WELSMAN,${ }^{1}$ E. C. MACLEOD,${ }^{1}$ A. W. SCHAAFSMA, ${ }^{2}$ \\ R. H. HALLETT, ${ }^{1,3}$ AND M. K. SEARS ${ }^{1}$
}

Environ. Entomol. 37(4): 973-979 (2008)

\begin{abstract}
Harmonia axyridis Pallas is an introduced lady beetle common in eastern North American agroecosystems. Two-choice behavioral bioassays were performed to determine whether visual and olfactory stimuli from prey and host habitats could elicit taxis in wild-collected $H$. axyridis adults and whether beetles exhibit a preference among stimuli. Soybean aphid (Aphis glycines Matsumura) spends much of the year in agricultural hedgerows residing on buckthorn (Rhammus cathartica $\mathrm{L}$ ), and H. axyridis is frequently observed feeding on aphids in this habitat. Olfactory bioassays were performed in a Y-tube olfactometer and tested the response of beetles to the odor of buckthorn leaves, apple leaves (Malus domestica Borkh.), and buckthorn leaves both naturally and artificially infested with A. glycines. No differences were observed between the numbers of beetles moving toward the odor of buckthorn artificially infested with A. glycines and uninfested buckthorn, but more beetles preferred naturally infested buckthorn over uninfested buckthorn. Visual bioassays were performed in an acrylic tube arena,and tested beetle response to silhouettes and to apple and buckhorn leaves. Beetles were significantly more likely to choose silhouettes over blank space in visual trials. Significantly more beetles moved toward buckthorn leaves than blank space, but beetles did not discern between apple and buckthorn until olfactory cues were also included. This study lays the foundation for future work examining the response of $\mathrm{H}$. axyridis to visual and olfactory cues in Ontario agroecosystems, which could help enhance effectiveness of $H$. axyridis as a biological control and mitigate its impacts as a pest species.
\end{abstract}

KEY WORDS Harmonia axyridis, preference assay, soybean aphid, Aphis glycines, buckthorn

Multicolored Asian lady beetle, Harmonia axyridis Pallas (Coleoptera: Coccinellidae), is found in a wide variety of agroecosystems in southern Ontario throughout the growing season feeding on a variety of aphid species (Homoptera: Aphididae) (Koch 2003, Ker and Carter 2004). Large aphid populations are required to support populations of $H$. axyridis, and such abundance of aphids is often ephemeral (Evans 2003). In the Great Lakes region of North America, $H$. axyridis has acquired status as both an important biological control organism for aphids in cultivated soybean (Fox et al. 2004) as a pest of fruit such as apples, raspberries, and pumpkins (Kovach 2004), and as an occasional economic pest of grapes in Ontario (Ker and Carter 2004). H. axyridis will move among habitats throughout the growing season, typically moving to locations of high prey abundance (Koch 2003). Olfactory cues may play only a minor role in the migratory and foraging behaviors of $H$. axyridis (Nalepa et

\footnotetext{
${ }^{1}$ Department of Environmental Biology, University of Guelph, Guelph, Ontario, Canada N1G 2W1.

${ }^{2}$ Department of Plant Agriculture, Ridgetown Campus, University of Guelph, 120 Main Street, Ridgetown, Ontario, Canada NOP 2C0.

${ }_{3}^{3}$ Corresponding author, email: rhallett@uoguelph.ca.
}

al. 2000); when migrating to overwintering sites or seeking out prey habitats, $H$. axyridis will move toward, and form aggregations on, prominently silhouetted objects on a horizon (Obata 1985, Koch 2003).

Many temperate aphid species alternate between a primary, woody overwintering host and a secondary, herbaceous summer host (Moran 1992). Since its discovery in North America in 2000, soybean aphid, Aphis glycines Matsumura (Homoptera: Aphididae), has become extremely abundant in the northeastern United States and southern Canada (Ragsdale et al. 2004). Soybean aphid is an important food source of $\mathrm{H}$. axyridis (Fox et al. 2004). In Ontario, H. axyridis has been observed feeding on A. glycines on both its summer host, soybean, and its winter host, buckthorn, Rhamnus cathartica $\mathrm{L}$., an exotic invasive shrub found frequently in agricultural hedgerows (Welsman et al. 2007). We have observed foraging $H$. axyridis in large numbers in agricultural hedgerows in both spring and autumn, coinciding with spring eclosion of A. glycines from overwintering eggs on $R$. cathartica and with reproductive generations of the aphid on this host in autumn. 
Because of the widespread use of lady beetles as biological control, the foraging behavior of many species of lady beetles has been studied, specifically with respect to searching behaviors involved with prey location (Dixon 1959, Nakamuta 1983, 1984a, b, Nakamuta and Saito 1985, Obata 1985, Hattingh and Samways 1995, Mondor and Warren 2000, Schaller and Nentwig 2000). Other natural enemies of aphids such as parasitic wasps rely on aphid host plant cues to locate their prey (Du et al. 1998), and recently, the ladybeetle Coccinella septempunctata L. has been shown to respond to plant volatiles induced by the feeding of soybean aphids (Zhu and Park 2005). Volatiles collected from the headspace surrounding aggregated females proved attractive to males of $H$. axyridis, and aphid alarm pheromones attracted both males and females (Verheggen et al. 2007). However, the role of volatiles has been studied less in predatory coccinellid-prey interactions than in parasitoid-host interactions (Nakamuta and Saito 1985). Foraging behaviors in coccinellids previously were thought to be based primarily on random-walk patterns (Hodek 1973), but a number of studies suggest the importance of tactile, gustatory, visual, and olfactory cues (each of which may be specific to a prey item, host plant, or habitat) in modulating nonrandom search patterns (Stubbs 1980, Nakamuta 1983, 1984a, b, Nakamuta and Saito 1985, Obata 1985, Hattingh and Samways 1995, Obata 1997, Schaller and Nentwig 2000). The random-walk pattern hypothesis for foraging in coccinellids assumes that prey detection only occurs with physical contact (Banks 1954, Kehat 1968). Under the random-walk foraging model, intensive and extensive random walk search enhances foraging success with aggregated prey. After encountering a prey item, a beetle will increase turning frequency and decrease walking speed to increase the likelihood of encountering a nearby prey item (i.e., intensive searching) (Hodek 1973). If no prey items are encountered after a period of intensive search, the extensive search pattern, marked by an increase in speed of movement and decreased turning, is resumed (Carter and Dixon 1982). Several studies have since reported the use of additional cues associated with prey and prey host plants in the enhancement of foraging success in coccinellids; adults or larvae move toward visual and olfactory cues associated with prey, prey hosts, feeding damage on prey hosts, and/or prey waste products (Stubbs 1980, Nakamuta 1983, 1984a, b, Nakamuta and Saito 1985, Obata 1985, Hattingh and Samways 1995, Obata 1997, Schaller and Nentwig 2000). Conditioning based on previous experience may also play an important role in the foraging of $H$. axyridis (Mondor and Warren 2000).

This study examines the roles of visual and olfactory cues from selected components of a hedgerow ecosystem in the foraging of $H$. axyridis. Specific objectives were to determine whether simulated odors and visual cues derived from $R$. cathartica, Malus domestica Borkh. (domestic apple), and A. glycines could elicit taxis toward the source from adult $H$. axyridis, and if so, to determine whether $H$. axyridis exhibit prefer- ences for certain of these stimuli. The results of this study should provide information regarding the cues used in foraging of $H$. axyridis, which may provide insight into the mechanisms behind the pest behavior of this species.

\section{Materials and Methods}

Experimental System. Response of $H$. axyridis to olfactory and visual cues originating from $R$. cathartica, M. domestica Borkh. (domestic apple), and A. glycines was tested using two-choice behavioral bioassays in two different arena types. $M$. domestica was selected as the experimental control because of its prevalence in agricultural hedgerows, its superficial resemblance to $R$. cathartica in leaf shape, and its lack of host association with A. glycines in Ontario (OMAFRA 2006).

Insect and Plant Material. In spring and summer 2006 , adult $H$. axyridis were collected from the wild in the vicinity of Ridgetown, Ontario, Canada $\left(42.35^{\circ} \mathrm{N}\right.$, $\left.81.84^{\circ} \mathrm{W}\right)$. Beetles were maintained in captivity in mesh cages for 24-72 h before experimentation at a photoperiod of $16 \mathrm{~L}: 8 \mathrm{D}$ and $21 \pm 2{ }^{\circ} \mathrm{C}$ and were provided with moistened paper toweling and sliced spoiled grapes ad libitum. A random allotment of beetles was removed from the cages, placed in plastic containers, and starved for $24 \mathrm{~h}$ before their use in experiments. Branch segments of $M$. domestica and $R$. cathartica were collected from agricultural hedgerows and ornamental plantations at Guelph, Ontario, Canada $\left(43.59^{\circ} \mathrm{N}, 80.27^{\circ} \mathrm{W}\right)$. New plant material was collected before each repetition.

Specimens of A. glycines for artificial infestation of R. cathartica were obtained from a laboratory culture maintained at the University of Guelph Ridgetown Campus, Ridgetown, Ontario, Canada. Foliage of $R$. cathartica with natural infestation of $A$. glycines was obtained in autumn 2006 from several ornamental shrubs growing on the University of Guelph Campus, Guelph, Ontario, Canada. Identification of insect specimens used in experiments was accomplished by comparison to published keys (Voegtlin et al. 2004).

Olfactometry Assays. A glass Y-tube olfactometer (Fig. 1) was used to test adult $H$. axyridis preferences for olfactory cues derived from $R$. cathartica, $M$. domestica, and A. glycines in isolation from other relevant cues. The following treatment pairs were examined: (1) R. cathartica foliage versus blank air, (2) R. cathartica foliage versus $M$. domestica foliage, (3) $R$. cathartica foliage alone versus $R$. cathartica foliage artificially infested with A. glycines, and (4) R. cathartica foliage versus $R$. cathartica foliage naturally infested with A. glycines (leaves for both treatments were taken from the same plants). Four repetitions, each consisting of 10 trials with single beetles, were performed in randomized order for each of the first three treatment pairs using new plant material and new aphids for each repetition; these trials were performed in May and June 2006. The final treatment was performed in four sequential repetitions of 10 beetles, with new plant and aphid material for each repetition, 


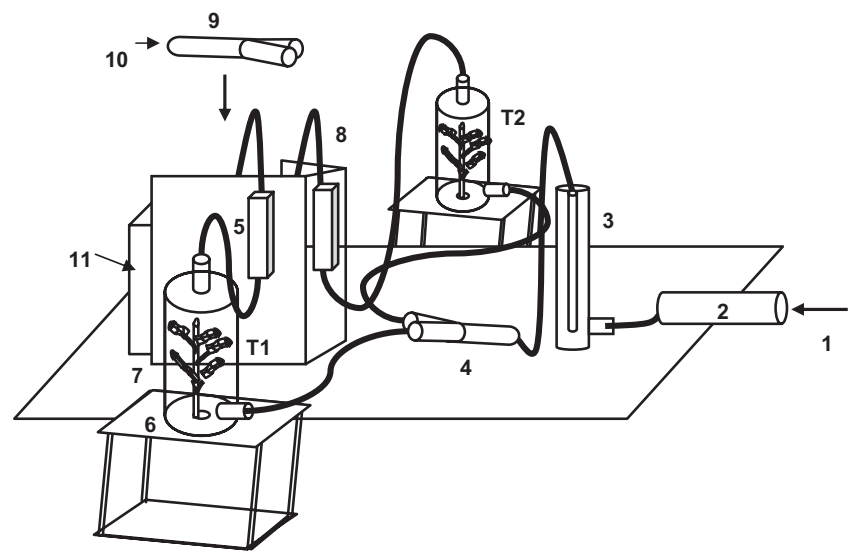

Fig. 1. Schematic of Y-tube olfactometer used for assays examining the behavior of H. axyridis in response to olfactory cues originating from a hedgerow ecosystem: (1) direction of air flow, (2) activated charcoal filter, (3) air stream humidifier, (4) glass Y-tube, (5) flow meter, (6) bell jar support base, (7) glass bell jar functioning as a volatile collection chamber containing plant/insect material, (8) conduits made of Teflon semiflexible tubing, (9) glass Y-tube olfactometer arena, (10) entry port for insect introduction into arena, (11) mesh-covered frame to enclose olfactometer. Purified, humidified air was blown over samples in bell jars. Each of the treated airstreams (T1, T2) was fed into an arm of the olfactometer. Adult beetles were placed individually in the arena through its entry port.

in October 2006, because naturally aphid-infested $R$. cathartica were unavailable earlier in the season.

Treatments consisted of $5 \mathrm{~g}$ of foliage from $R . c a-$ thartica or M. domestica that had been removed from branches and placed loosely in the bottom of one of the two bell jars. Foliage was examined visually to exclude leaves with insects and insect damage and rinsed in distilled water and allowed to air dry before use. For leaves artificially infested with aphids, rinsed foliage of $R$. cathartica was infested with A. glycines by placing two to three laboratory-cultured aphids on each leaf in the 5 - $g$ foliage sample $\approx 30$ min before use in experiments. Artificially infested foliage was used to examine the response of $H$. axyridis to foliage with aphids that had not had a chance to induce volatiles because of feeding damage or honeydew. Foliage of $R$. cathartica infested naturally with A. glycines was obtained by gathering leaves with two to three aphids present on each from shrubs with autumn aphid populations. Leaves with aphids were left unwashed to preserve any volatiles originating from honeydew or feeding damage.

All experiments took place in a windowless laboratory. Insect and plant material were housed in a glass bell jar and connected to the olfactometer by Teflon semiflexible tubing. All joints were sealed with Teflon tape. Components of the olfactometer system subsequent to the charcoal filter, including juncture seals, were manufactured from materials that emit no organic volatile compounds (e.g., glass and Teflon). Most components were obtained from Analytical Research Systems (Gainesville, FL).

The olfactometer was housed in a frame made of double-sided mesh to provide diffuse light. Light was provided by two banks of Sylvania $60-\mathrm{W}$ fluorescent bulbs mounted at equal distances and heights above the olfactometer. Bell jars were placed outside of the mesh frame and behind black walls to remove the influence of visual stimuli on insect behavior. Air was passed through an activated charcoal filter and humidified to at least $70 \%$ RH by passing the air stream through a column of distilled water. Air stream temperature was maintained at $23 \pm 11^{\circ} \mathrm{C}$ throughout the experiment. The relative humidity and temperature of air exiting the olfactometer was measured using a hygrometer (Mannix, New York, NY) before the beginning of each repetition. Air flow rate was regulated by flow meters (Key Instruments, Trevose, PA) and maintained at 1 liter/min entering each arm of the olfactometer; air flow was equalized before the beginning of each trial involving a new insect.

Treated air streams were assigned randomly to an arm of the Y-tube based on a coin toss at the beginning of each trial. Before introducing each insect to the arena, the Y-tube arena was washed with denatured ethanol and air-dried with compressed, purified air passed through a charcoal filter.

Individuals were placed in the arena through the entry port at the base of its main arm, and their movements were observed. Choice was recorded when the subject insect moved past a "choice line" located $5 \mathrm{~cm}$ past the junction of the two arms, toward one of the olfactory sources. Beetles not moving past the choice line within $10 \mathrm{~min}$ were recorded as nonresponders and excluded from analysis.

Shape Preference Assays. Vertical and horizontal silhouettes were used to examine beetle preference for visual stimuli in an I-tube arena. The following treatment pairs were examined: horizontal bars versus blank space, vertical bars versus blank space, and horizontal bars versus vertical bars. An open-ended clear acrylic tube $120 \mathrm{~cm}$ long by $12 \mathrm{~cm}$ diameter (Sterling Creations, Guelph, Ontario, Canada) was placed in a 50 by 50 by $130-\mathrm{cm}$ white cotton tent in a darkened room (Fig. 2). Any air flow occurring in the arena was passive, and the tent functioned to minimize any out- 


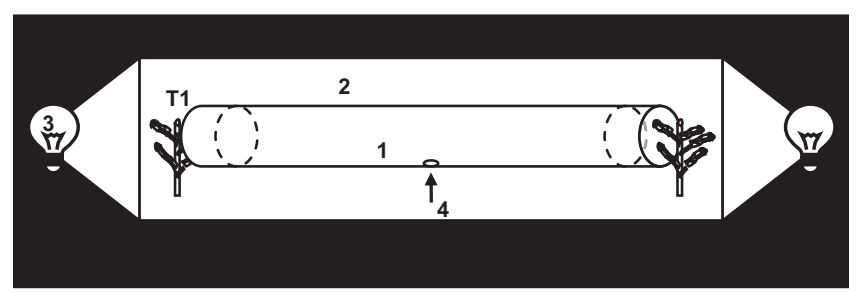

Fig. 2. Schematic of I-tube arena used for assays examining the behavior of $H$. axyridis in response to olfactory and visual cues originating from a hedgerow ecosystem. The assembly consisted of a 120-cm-long by 12-cm-diameter, open-ended, clear acrylic tube (1) placed in a 50 by 50 by $130-\mathrm{cm}$ white fabric tent (2) in a darkened room. Each end of the tent was illuminated with an identical spotlight (3). Treatment pairs (T1, T2) were placed at opposite ends of the tube. Adult beetles were placed individually in the arena through a 1-cm-diameter hole drilled at the center of its length (4).

side air currents from natural air movement in the room. The white tent was suspended on a frame constructed of white 1-in PVC tubing and placed on a 70 by $140-\mathrm{cm}$ table. Each end of the tent was illuminated from the outside with an identical 150 -W incandescent spotlight attached to the table at the center of its width. Treatment pairs were placed at opposite ends of the tube, inside the tent, and attached to the frame of the enclosure. The horizontal bar treatment was made using five 5 -cm-wide by 50 -cm-long strips of black foam-core board affixed to the frame of the tent horizontally at $5-\mathrm{cm}$ intervals. The vertical bar treatment was made using bars identical to the horizontal treatment, attached vertically to the tent frame, with the same white space present between bars. Before each repetition, the arena was rinsed with denatured ethanol and air dried. Before the introduction of each subject insect, a coin toss determined whether the tube was to be rotated $180^{\circ}$ to randomize the end of the tube pointing at each treatment in the treatment pair. From June through September 2006, assays of six repetitions, each consisting of 10 individual adults of H. axyridis for each treatment pair, were performed in randomized order. Subject insects were placed individually in the I-tube arena by placing them on a plastic lid from a vial and raising them through a 1-cm-diameter hole drilled at the midpoint of its length in the bottom of the tube. Choice was recorded when a subject insect passed a "choice line" located 20 $\mathrm{cm}$ from the treatment stimulus. Beetles not crossing the choice line within 5 min were recorded as nonresponders and excluded from analysis.

Foliage Preference Assays. The I-tube arena described above was also used to test the preference of $H$. axyridis for foliage of R. cathartica and M. domestica with and without olfactory cues. The following treatment pairs were examined: $R$. cathartica excluding odor versus blank space, $R$. cathartica excluding odor versus $R$. cathartica including odor, $R$. cathartica excluding odor versus $M$. domestica excluding odor, and $R$. cathartica including odor versus $M$. domestica including odor. Each foliage treatment consisted of 10 foliated twigs $\approx 20 \mathrm{~cm}$ in length, rinsed in distilled water and air dried for $\approx 30 \mathrm{~min}$, held erect in wet floral foam in a white-painted 591-ml plastic container. If a treatment was to exclude odor, a piece of plastic cling wrap was affixed over the relevant end of the I-tube with a beige colored rubber band. Treatment pairs were placed at opposite ends of the tube, on the table, inside the fabric tent. Six repetitions of 10 beetles were performed for each treatment pair in randomized order, using new plant material for each repetition. Subject insects were placed individually in the I-tube arena through the small hole drilled at the midpoint of its length and observed. Choice was recorded when a subject insect passed a "choice line" located $20 \mathrm{~cm}$ from the treatment stimulus. Beetles not crossing the choice line within 5 min were recorded as nonresponders and excluded from analysis.

Statistical Analyses. All analyses were conducted in SAS 9.1.3 (SAS Institute, Cary, NC) using PROC FREQ. Choice distributions for each treatment pair in all assays were subjected to a $\chi^{2}$ goodness-of-fit analysis to determine whether the choice response deviated significantly from random (1:1 ratio of choice for each treatment in the pair). A significance level of $\alpha=$ 0.05 was used for all analyses, and only statistically significant differences are reported.

\section{Results}

Several treatment-pair comparisons yielded significant, nonrandom results in each assay type (Table 1). From 65.0 to $98.3 \%$ of beetles made a choice depending on the treatment pair.

Olfactometry Assays. Harmonia axyridis moved toward the odor of $R$. cathartica leaves in absence of other stimuli (Table 1) but preferred the odor of $M$. domestica foliage over that of $R$. cathartica foliage. $H$. axyridis was not able to discern between odors of $R$. cathartica artificially infested with aphids and $R$. $c a$ thartica without aphids, but a strong preference was observed for the odor of $R$. cathartica foliage naturally infested with A. glycines over clean R. cathartica foliage.

Shape Preference Assays. Harmonia axyridis moved toward both vertical and horizontal bars in the absence of other visual stimuli (Table 1). Beetles did not discriminate between horizontal and vertical bars.

Foliage Preference Assays. Foliage of R. cathartica was more visually attractive to $H$. axyridis than the control blank space (Table 1). H. axyridis preferred $R$. cathartica foliage with olfactory stimuli than the visual stimuli alone. H. axyridis exhibited no preference be- 
Table 1. Observed preferences of wild-collected adult $H$. axyridis for various stimuli derived from a hedgerow ecosystem in two different arena types

\begin{tabular}{|c|c|c|c|c|c|c|c|c|}
\hline \multirow{2}{*}{ Arena type } & \multicolumn{2}{|r|}{ Comparison } & \multirow{2}{*}{$N$} & \multirow{2}{*}{$\%$ Response } & \multicolumn{2}{|c|}{ \% Choice } & \multirow{2}{*}{$\chi^{2}$} & \multirow{2}{*}{$P$} \\
\hline & $\mathrm{T} 1$ & $\mathrm{~T} 2$ & & & $\mathrm{~T} 1$ & $\mathrm{~T} 2$ & & \\
\hline \multicolumn{9}{|c|}{ Olfactometry assays } \\
\hline Y tube & R. cathartica odor & Blank & 30 & 75.0 & 70.0 & 30.0 & 4.8 & $0.029^{a}$ \\
\hline Y tube & R. cathartica odor & M. domestica odor & 31 & 77.5 & 32.3 & 67.7 & 3.9 & $0.048^{a}$ \\
\hline Y tube & R. cathartica odor & Artificially aphid infested $R$.cathartica odor & 32 & 80.0 & 53.1 & 46.9 & 0.1 & 0.724 \\
\hline Y tube & R. cathartica odor & Naturally aphid infested $R$. cathartica odor & 38 & 95.0 & 31.6 & 68.4 & 5.2 & $0.023^{a}$ \\
\hline \multicolumn{9}{|c|}{ Shape preference assays } \\
\hline I tube & Horizontal bars & Blank & 39 & 65.0 & 66.7 & 33.3 & 4.3 & $0.037^{a}$ \\
\hline I tube & Vertical bars & Blank & 43 & 71.7 & 65.1 & 34.9 & 3.9 & $0.047^{a}$ \\
\hline I tube & Horizontal bars & Vertical bars & 55 & 91.7 & 43.6 & 56.4 & 0.89 & 0.345 \\
\hline \multicolumn{9}{|c|}{ Foliage preference assays } \\
\hline I tube & R. cathartica without odor & Blank & 46 & 76.7 & 69.6 & 30.4 & 7.0 & $0.008^{a}$ \\
\hline I tube & R. cathartica without odor & R. cathartica with odor & 43 & 71.7 & 32.6 & 67.4 & 5.2 & $0.022^{a}$ \\
\hline I tube & R. cathartica without odor & M. domestica without odor & 54 & 90.0 & 53.7 & 46.3 & 0.3 & 0.586 \\
\hline I tube & R. cathartica with odor & M. domestica with odor & 59 & 98.3 & 71.2 & 28.8 & 10.6 & $0.001^{a}$ \\
\hline
\end{tabular}

A Y-tube olfactometer was used to test adult preference for olfactory cues derived from R. cathartica and A. glycines. An I-tube flight chamber was used to test adult preference for silhouetted shapes and to plant material with and without odor stimuli. Choice distributions were subjected to $\chi^{2}$ goodness-of-fit analysis to determine whether the response was random at $\alpha=0.05$. Number of $H$. axyridis adults, percent choosing each treatment, Yates-corrected $\chi^{2}$ statistics, and $P$ values are given.

${ }^{a}$ Significant, nonrandom responses.

tween visual stimuli of $R$. cathartica and $M$. domestica when olfactory stimuli were absent, but a strong preference for $R$. cathartica was observed when both visual and olfactory stimuli were present.

\section{Discussion}

Volatiles associated with undamaged $R$. cathartica foliage elicited a response in adult $H$. axyridis, but beetles were preferentially attracted to $R$. cathartica with actively feeding natural populations of $A$. glycines. No such preference was observed for $R$. cathartica foliage infested artificially with A. glycines, suggesting that volatiles associated with prey feeding damage on a host and prey waste products may play a more important role in prey-finding of $H$. axyridis than volatiles associated with prey items alone. This treatment likely did not provide sufficient time for aphids to produce a significant amount of honeydew or other olfactory cues associated with feeding damage. Olfactory cues from prey items or their byproducts (such as honeydew) assure a beetle of the presence (or recent presence) of prey, yet a number of previous studies involving direct aphid scent cues alone do not support this finding (Nakamuta 1991, Schaller and Nentwig 2000).

When damaged by herbivores, plants may release volatile semiochemicals that are used by natural enemies seeking herbivorous prey (Schaller and Nentwig 2000). This chemical signaling by the plant may provide an adaptive advantage to both the plant and natural enemy of an herbivore attacking the plant by shortening search times required to find and kill pest insects (Hattingh and Samways 1995). Volatiles associated with $R$. cathartica were able to elicit responses in $H$. axyridis even in the absence of prey items in our study. Olfactory cues from plants undamaged by herbivores could be employed in foraging for a number of reasons. Diets of many predaceous coc- cinellids consist mainly of aphids and other soft bodied arthropods, but often include small amounts of pollen and other plant tissues (Schaller and Nentwig 2000). Plant olfactory cues could thus play an important role in coccinellid foraging behavior because, in addition to seeking prey item habitats and hosts, the lady beetle may also be seeking out plant food, oviposition sites, or mates (Schaller and Nentwig 2000). Olfactory cues from an herbivore host plant may play a role in sustaining a natural predator population to keep herbivorous insect populations in check (Dicke and Sabelis 1988).

Visual cues play important roles in host-finding, but studies are conflicting as to the scale at which they act and as to the visual acuity of lady beetles. This study suggests that adult $H$. axyridis rely on long range visual cues to locate host habitats: $H$. axyridis will move toward both silhouetted shapes and leaves of preyhost plants, even when scent cues are eliminated. Similarly, Hattingh and Samways (1995) found that $C$. nigritus adults were attracted to simulated horizons and were attracted preferentially to horizons that simulated treelines over flat horizons.

When presented in isolation in the Y-tube assays, $H$. axyridis preferred the odor of $M$. domestica foliage over that of $R$. cathartica foliage, but in the I-tube assays, when presented with both types of foliage with odor, a strong preference for $R$. cathartica was observed. This apparent contradiction may have been caused by a number of factors. It is possible that beetles behave differently in the presence of visual stimuli, but it is more likely that other factors could have affected this result. Assays performed in the Y-tube arena were conducted in May and June 2006 using leaves collected from local populations of $M$. domestica and R. cathartica, whereas the I-tube assays involving foliage were conducted in July and August 2006 using leaves from plants in the same area. It is thus possible that leaf age plays an important role in its 
attractiveness to $H$. axyridis, and beetles prefer younger $M$. domestica leaves but older $R$. cathartica leaves. Future work should specifically examine the effect of leaf age on attractiveness to $H$. axyridis.

Obata (1997) asserted that H. axyridis uses both olfactory and visual cues to detect prey "from a distance"; however, different cues for foraging may vary in importance at different scales. At a more distant spatial scale, visual cues seem to be most important in finding suitable prey habitats, as was observed in this study with $H$. axyridis, and for C. nigritus preferentially moving toward simulated treelines (Hattingh and Samways 1995). Within a prey habitat, cues associated with finding prey host plants are largely visual (Hattingh and Samways 1995), but some plants are known to be attractive to C. septempunctata (Schaller and Nentwig 2000).

Harmonia axyridis has status as a pest in Ontario. In early autumn, $H$. axyridis has been observed to aggregate on grape clusters as they ripen, and these beetles may be harvested with ripened grapes (Ker and Carter 2004). When processed with the grapes, chemicals produced by $H$. axyridis can adversely affect the quality of wines and juices (Pickering et al. 2004). Ecological mechanisms responsible for aggregation of $H$. axyridis on grapes in autumn are unknown, and explanations proposed to date are speculative: no large populations of aphids are known to occur in Ontario vineyards in late autumn (N. Carter, personal communication). Aggregations of H. axyridis in vineyards are often associated with damage or overripening of the fruit (Ker and Carter 2004, Pervez and Omkar 2006).

A better understanding of cues used by $H$. axyridis in foraging may explain why beetles aggregate on grape vines. We observed $H$. axyridis in agricultural hedgerows in autumn, foraging on $R$. cathartica and feeding on A. glycines. Beetles are more numerous in hedgerows in years when very few beetles are present in vineyards (Bahlai 2007). When aphids are not numerous in hedgerows, beetles may use similar cues to find their way to vineyards. Fermentation products associated with ripe or damaged grapes may be similar to fermentation products of honeydew and thus be attractive to $H$. axyridis. Future work should examine the response of $H$. axyridis to specific volatiles associated with aphids and grape varieties, as well as chemical analyses of these volatiles. Studies should also incorporate satiated and starved beetles to compare responses to stimuli in that context; a beetle that is satiated on aphids may have different feeding preferences and foraging behaviors than a beetle that was starved.

\section{Acknowledgments}

The authors thank J. Schmidt for comments on the design and interpretation of this study, anonymous reviewers for helpful comments, and technicians K. Eddington and C. Smith for laboratory support. Financial support was provided by the Wine Council of Ontario, the Grape Growers of
Ontario, and the Ontario Ministry of Agriculture and Food, and Rural Affairs.

\section{References Cited}

Bahlai, C. A. 2007. Ecological interactions of Harmonia axyridis and Aphis glycines in Ontario agroecosystems. MSc thesis, Department of Environmental Biology, University of Guelph, Guelph, Canada.

Banks, C. J. 1954. The searching behaviour of coccinellid larvae. Br. J. Anim. Behav. 2: 37-38.

Carter, M. C., and A.F.G. Dixon. 1982. Habitat quality and foraging behavior of coccinellid larvae. J. Anim. Ecol. 51: $865-878$.

Dicke, M., and M. W. Sabelis. 1988. How plants use predatory mites as bodyguards. Neth. J. Zool. 38: 148-165.

Dixon, A.F.G. 1959. An experimental study of the searching behavior of the predatory coccinellid beetle Adalia decempunctata (L.). J. Anim. Ecol. 28: 259-281.

Du, Y., G. M. Poppy, W. Powell, J. A. Pickett, L. J. Wadhams, and C. M. Woodcock. 1998. Identification of semiochemicals released during aphid feeding that attract parasitoid Aphidius ervi. J. Chem. Ecol. 24: 1355-1368.

Evans, E. W. 2003. Searching and reproductive behaviour of female aphidophagous ladybirds (Coleoptera: Coccinellidae): a review. Eur. J. Entomol. 100: 1-10.

Fox, T. B., D. A. Landis, F. F. Cardoso, and C. D. Difonzo. 2004. Predators suppress Aphis glycines Matsumura population growth in soybean. Environ. Entomol. 33: 608618.

Hattingh, V., and M. J. Samways. 1995. Visual and olfactory location of biotopes, prey patches, and individual prey by the lady beetle Chilocorus nigritus. Entomol. Exp. Appl. 75: $87-98$

Hodek, I. 1973. Biology of the Coccinellidae. Academia, Prague, Czech Republic.

Kehat, M. 1968. Feeding behavior of Pharoscymnus numidicus (Coccinellidae), predator of the date palm scale. Entomol. Exp. Appl. 11: 30-42.

Ker, K. W., and N. Carter. 2004. Questions and answers about Harmonia axyridis (Pallas). (http://brocku.ca/ ccovi/news/MALB QA 2004 update.pdf).

Koch, R. L. 2003. The multicolored Asian lady beetle, Harmonia axyridis: a review of its biology, uses in biological control, and non-target impacts. J. Insect Sci. 3: 1-16.

Kovach, J. 2004. Impact of the multicolored Asian lady beetle as a pest of fruit and people. Am. Entomol. 50: 165-167.

Mondor, E. B., and J. L. Warren. 2000. Unconditioned and conditioned responses to colour in the predatory coccinellid, Harmonia axyridis (Coleoptera: Coccinellidae). Eur. J. Entomol. 97: 463-467.

Moran, N. A. 1992. The evolution of aphid life cycles. Annu. Rev. Entomol. 37: 321-348.

Nakamuta, K. 1983. Sequence of predatory behavior of the ladybeetle, Coccinella septempunctata L. (Coleoptera: Coccinellidae) on the green peach aphid, Myzus persicae Sulzer (Homoptera: Aphididae). Appl. Entomol. Zool. 18: $559-561$.

Nakamuta, K. 1984a. Aphid body fluid stimulates feeding of a predatory ladybeetle, Coccinella septempunctata L., (Coleoptera: Coccinellidae). Appl. Entomol. Zool. 19: 123-125.

Nakamuta, K. 1984b. Visual orientation of a ladybeetle, Coccinella septempunctata L. (Coleoptera: Coccinellidae), towards its prey. Appl. Entomol. Zool. 19: 82-86.

Nakamuta, K. 1991. Aphid alarm pheromone component, (E) $-\beta$-farnesene, and local search by a predatory lady 
beetle, Coccinella septempunctata brukii Mulsant. (Coleoptera: Coccinellidae). Appl. Entomol. Zool. 26: 1-7.

Nakamuta, K., and T. Saito. 1985. Recognition of aphid prey by the lady beetle, Coccinella septempunctata brukii Mulsant, (Coleoptera: Coccinellidae). Appl. Entomol. Zool. 20: $479-483$.

Nalepa, C. A., K. A. Kidd, and D. I. Hopkins. 2000. The multicolored Asian ladybeetle (Coleoptera: Coccinellidae): orientation to aggregation sites. J. Entomol. Sci. 35: $150-157$.

Obata, S. 1985. Mechanisms of prey finding in the aphidophagous ladybird beetle, Harmonia axyridis (Coleoptera: Coccinellidae). Entomophaga 31: 303-311.

Obata, S. 1997. The influence of aphids on the behavior of adults of the ladybird beetle, Harmonia axyridis (Col.: Coccinellidae). Entomophaga 42: 103-106.

[OMAFRA] Ontario Ministry of Agriculture, Food and Rural Affairs. 2006. Fruit production recommendations 2006-2007. Ontario Ministry of Agriculture, Food and Rural Affairs, Ontario, Canada.

Pervez, A., and Omkar. 2006. Ecology and biological control application of the multicoloured Asian ladybird, Harmonia axyridis: a review. Biocontrol. Sci. Technol. 16: 111128.

Pickering, G., J. Lin, R. Riesen, A. Reynolds, I. Brindle, and G. Soleas. 2004. Influence of Harmonia axyridis on the sensory properties of white and red wine. Am. J. Enol. Vitic. 55: 153-159.
Ragsdale, D. W., D. J. Voegtlin, and R. J. O’Neil. 2004. Soybean aphid biology in North America. Ann. Entomol. Soc Am. 97: 204-208.

Schaller, M., and W. Nentwig. 2000. Olfactory orientation of the seven-spot ladybird beetle, Coccinella septempunctata (Coleoptera: Coccinellidae): attraction of adults to plants and conspecific females. Eur. J. Entomol. 97: 155159.

Stubbs, M. 1980. Another look at prey detection by coccinellids. Ecol. Entomol. 5: 179-182.

Verheggen, F. J., Q. Fagel, S. Heuskin, G. Lognay, F. Francis, and E. Haubruge. 2007. Electrophysiological and behavioral responses of the multicolored Asian lady beetle, Harmonia axyridis Pallas, to sesquiterpene semiochemicals. J. Chem. Ecol. 33: 2148-2155.

Voegtlin, D. J., S. E. Halbert, and G. Qiao. 2004. A guide to separating Aphid glycines Matsumura and morphologically similar species that share its hosts. Ann. Entomol. Soc. Am. 97: 227-232

Welsman, J. A., C. Bahlai, M. Sears, and A. Schaafsma. 2007. Decline in soybean aphid (Homoptera: Aphididae) egg populations from autumn to spring on the primary host Rhamnus cathartica L. Environ. Entomol. 36: 541-548.

Zhu, J., and K. C. Park. 2005. Methyl salicylate, a soybean aphid-induced plant volatile attractive to the predator Coccinella septempunctata. J. Chem. Ecol. 31: 1733-1746.

Received 4 December 2007; accepted 6 May 2008 